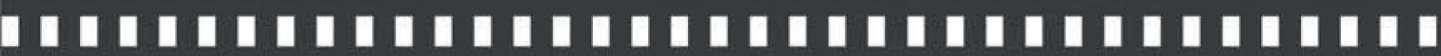

\author{
0 risco do real e emancipação em Moscou: \\ o filme-dispositivo como estratégia de \\ questionamento de dispositivos sociais
}

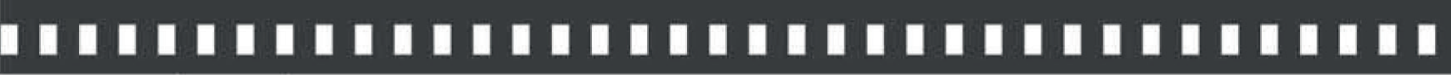

Nilson Assunção Alvarenga

Thalita Gonçalves Rocha 


\title{
0 risco do real e emancipação em Moscou: o filme- dispositivo como estratégia de questionamento de dispositivos sociais
}

The risk of real and emancipation in Moscou: the dispositif film as questioning
strategy of social dispositifs

Nilson Assunção Alvarenga*

Thalita Gonçalves Rocha**

Resumo: Partindo do debate contemporâneo sobre o documentário desde Jean-Louis Comolli, pretende-se uma leitura de Moscou, de Eduardo Coutinho, pensando-o como um filme em que, pela multiplicação de referentes das falas e ações dos atores em cena, abre-se o horizonte de um "risco do real" e assim coloca-se em questão os próprios dispositivos sociais, no sentido foucaultiano.

Palavras-chaves: : Dispositivo. Realidade. Real. Documentário.

\begin{abstract}
Starting from the contemporary discussion about the documentary since Jean-Louis Comolli, it is intended to do a reading of Moscow, by Eduardo Coutinho, thinking it as a film in which, by the multiplication of the speech referents and actions of the actors on the scene, it opens the horizon of a "real risk" and so it sets into question the own social dispoisitifs, in Foucault's sense.
\end{abstract}

Keywords: Dipositif. Reality. Real. Documentary.

\footnotetext{
* Professor Permanente do PPGCom/UFJF. Bacharel em Comunicação pela UFJF e doutor em Filosofia pela PUC-Rio.

** Mestra em Comunicação Social pelo Programa de Pós-Graduação em Comunicação da UFJF - PPGCom/UFJF.
} 


\section{Introdução}

Encontramos no cenário atual, tanto no terreno das representações midiáticas quanto no campo das artes, estratégias diversas de retomada de estéticas realistas. Atribuível, por um lado, ao próprio processo de globalização cultural, que torna urgente a valorização da paisagem local e do mundo vivido no cotidiano (LOPES, 2012) ou, por outro, a um esgotamento dos procedimentos artísticos pós-modernistas, em que a simulação, o jogo de referências e a metalinguagem maneirista eram estratégias recorrentes (SCHOLLHAMMER, 2012), o fato é que podemos dizer que hoje há uma generalizada demanda de realidade ou, em um sentido que tentaremos esclarecer, também uma demanda do real. Há demandas de real ou de realismo, em um extremo, no reality show, na teledramaturgia e na ficção seriada e, no outro, numa produção cinematográfica documental e ficcional importante, em que encontramos nomes como Hou Hsiao Hsien, Jia Zhan Ke, Tsai Ming Liang, João Moreira Salles, Eduardo Coutinho, dentre outros. Decorre disso que expressões como "retorno do real" (na leitura que Hal Foster fizera de Warhol e do hiperrealismo), no campo da crítica da arte, "choque do real" (JAGUARIBE, 2007), no âmbito da análise da mídia, "realismo afetivo" (SCHOLLAMMER, 2012), na retomada e revisão de um projeto realista, no terreno da literatura, surgem para pensar essa demanda e suas consequências. Recentemente, coletâneas como "Novos realismos" (MARGATO; GOMES, 2012) ou "Ensaios no real" (MIGLIORIN, 2010) mostram a importância do debate sobre estéticas do real, contrapondo, de forma recorrente, lógicas realistas midiáticas e artísticas.

Nesse contraponto entre respostas midiáticas (nas dinâmicas do espetáculo) e artísticas (de uma perspectiva crítica) a essa demanda, gostaríamos de destacar, de saída, uma diferença importante: entre aqueles produtos audiovisuais em que o que chamamos "real" entra como um referente, algo já interpretado ou já incorporado numa lógica representacional (um problema 
social específico, a situação política de um país, um personagem exemplar de uma situação definida; ou, no extremo, ou seja, no caso do reality show, uma disputa entre personagens em busca de um objetivo); e aqueles para os quais o "real" se apresenta como um problema - como algo não referenciável diretamente, portanto - e sua busca, um risco ${ }^{1}$. É assim, como algo indefinido, aberto e essencialmente ambíguo em suas implicações cognitivas, sociais e políticas que o real apareceria para Jean Louis Comolli (2008) em certo tipo de documentário e em certas ficções contemporâneas. E é nessa perspectiva de um cinema que se faz sob risco do real que aparecem os documentários de Eduardo Coutinho, tal como já apontado por diversos autores.

Moscou (2009) é especialmente importante para pensar que ideia de real é buscada no documentário contemporâneo. Intencionamos com nossa análise mostrar a potência de se lêlo como um filme que aciona o real através da estratégia da não atualização de referentes, uma vez que, neste documentário, não se trata mais nem de falar de uma realidade que existe previamente ao fato da filmagem, nem mesmo da configuração de um conjunto preciso de referentes (das falas e das imagens).

1 Embora sejam termos claramente complicados de definir, faremos neste artigo, por questão de definição operacional, uma distinção entre "realidade" e "real". Enquanto uma realidade poderia ser definida através de referentes precisos (a "realidade" social, política econômica de uma cidade; a situação de um certo grupo de pessoas etc.), o real só pode ser indicado por via indireta. A diferenciação em termos dos conceitos de ato e potência poderia ser útil (AGANBEM, 2006); mas seguimos, neste segundo caso, a compreensão lacaniana do real, como algo que escapa ao campo do significante. Na leitura que Hal Foster (2014) faz de Death in America, de Andy Warhol, as ideias de realismo traumático" e "retorno do real exploram esse conceito lacaniano de real como algo que não pode ser referido, mas apontado apenas através de abordagem indireta (explorando o trauma que, enquanto encontro faltoso com o real, precisa ser repetido para que se faça retornar esse mesmo real como aquilo que escapa ao campo dos referentes). Embora não seja possível explorar aqui em toda sua amplitude essa abordagem, pressuporemos que as análises de Foster, recorrendo ao conceito lacaniano de real, podem ser ampliadas para outros procedimentos que não aqueles especificamente utilizados por Warhol e pelos hiperrealistas, mas causando resultados análogos: uma abertura para o horizonte desse real como processo, nunca como referente dado de antemão ou mesmo como algo atualizado na obra. Pensamos que Moscou possa ser pensado a partir dessa noção de real. 
Sendo pertinente essa análise, poderemos dizer que Moscou não é sobre alguma coisa ou sobre certos personagens (como referentes reais), mas uma pura construção, um processo de produção de uma experiência real em toda sua ambiguidade, abertura e risco. Nessa experiência, situações, texto e personagens estão todos em estado não apenas incompleto, mas sob o risco de nunca se tornarem uma realidade definida; e por isso mesmo se mostram como algo real, o qual se vivencia como risco. Um risco que é, primeiro do diretor, mas que passa a ser também do espectador.

Por trazer a experiência do risco para o espectador, enxergamos nesse filme um potencial emancipatório: ao experienciar o risco, o espectador pode se dar conta de seus desejos e automatons de fabulação e, neste movimento, ele também pode tomar consciência do dispositivo fílmico.

Discorreremos sobre este potencial localizando-o dentro de uma perspectiva política em relação aos (e no interior dos) dispositivos sociais, finalizando com um questionamento: a interação/percepção com/dos dispositivos fílmicos pode fazer com que o espectador, por analogia, perceba configurações dos dispositivos sociais?

\section{"Sob o risco do real": o roteiro e o risco}

Em seu texto Sob o risco do real, Jean Louis Comolli pensa o problema do roteiro no cinema. Não, porém, somente a ideia técnica de roteiro, mas algo mais basal, que é o modo como o filme pode ou deve abordar a realidade. $\mathrm{O}$ autor retoma, com isso, aquela distinção sempre recorrente: entre uma construção ficcional midiática e um outro tipo de elaboração narrativa, que ele associa ao campo das artes, especialmente ao campo do documentário. Preocupa lhe a abordagem da realidade feita no documentário (embora, como ele mesmo chama atenção, obras de ficção também podem operar nesse sentido). Diferentemente da roteirização midiática co- 
mercial, marcada pelas características típicas da sociedade do espetáculo, encontraríamos um subconjunto de produção, uma "parcela obscura do espetáculo" que resiste e "mina o espetáculo generalizado" (COMOLLI, 2008, p. 173), a saber: o cinema documentário e certa ficção cinematográfica que se aventuram, operando "sob o risco do real" (COMOLLI, 2008, p. 169).

O roteiro, em sentido específico ${ }^{2}$, tal como ocorre na ficção do cinema comercial, própria à cultura (da sociedade) do espetáculo, conforme Comolli ${ }^{3}$, é um roteiro que não é outra coisa além do que uma espécie de réplica de um outro roteiro, mais amplo. Para o autor, "nossas fantasias e nossas necessidades são roteirizadas. Uma mão invisível alinha os processos supostos a nos conduzir" (COMOLLI, 2008, p.169). Ou seja, há um roteiro das relações de poder estabelecidas na sociedade, e os roteiros midiáticos e os cinematográficos cujo padrão é meramente comercial seriam réplicas daquele, as quais, ao mesmo tempo, promovem-no e garantem-no como inquestionáveis. Poderíamos dizer que a realidade, portanto, encontra-se filtrada por esse roteiro mais amplo de que nos fala Comolli (2008). Somente roteiros, em sentido especifico, que pudessem romper esses filtros, trabalhando sob o risco do real, poderiam questionar ou pelo menos complexificar esse "roteiro" em sentido amplo que previamente molda a realidade ${ }^{4}$.

Um comentário pertinente aqui poderia ser feito fazendo analogia com a ideia de Jacques Rancière segundo a qual o "modelo representacional" ou o "regime representacional das artes" é

2 Falaremos aqui em roteiro em sentido específico quando nos referirmos ao roteiro deste ou daquele filme; e "roteiro em sentido amplo" ao falarmos daquele roteiro pensado por Comolli (2008) como estruturante das relações sociais, o qual tentaremos entender à luz do conceito de dispositivo.

3 Poderíamos dizer isso não apenas da ficção comercial, mas também em alguns documentários; ou, então, na maior parte do material ficcional da televisão, a telenovela, por exemplo; e ainda poderíamos acrescentar também na ficção seriada e os reality shows. 4 Essa seria uma outra maneira de expressar que, em certos produtos audiovisuais contemporâneos, a presença de uma "realidade", isto é, um referente real, não garante que haja um risco na abordagem do real em sua abertura e, portanto, sua potência. A presença de referentes reais não garante que possamos romper os filtros daquele roteiro em sentido amplo que nos fala Comolli (2008). 
correlato de um sistema de organização social aristocrático e hierárquico (RANCIÈRE, 2001). As narrativas de superação catártica, próprias do cinema comercial e de grande parte da teledramaturgia, por exemplo, contrariamente àqueles que tentaram entendê-lo como arte por excelência do regime estético das artes (RANCIÈRE, 2001, p. 32), seguem ainda o modelo poético da ficção, característico do regime representacional, baseando-se, assim, no modelo de um agente causal a quem é dada clareza de intenção e ação e o direito de agir conforme a fins, na busca de obtenção de seus objetivos. Ora, transferir conteúdos da realidade (social, política, cultural etc.) para dentro desse modelo não garante a potência desse real representado. Se é assim na ficção, também poderá ser no caso do documentário: não bastaria tratar de temas urgentes, de questões da realidade, atuais ou passadas para fazer jus à potência de real existente nas situações e personagens filmadas. Explorar o real à luz de um modelo que o sufoca - e este seria, a nosso ver, o roteiro cinematográfico que apenas, na opinião de Comolli (2008), garante aquele outro roteiro, o que ordena e conduz nossas fantasias e necessidades - não seria a maneira de atender àquela demanda de realidade. É preciso transformar a demanda de realidade em demanda de real, no sentido que estamos usando aqui.

De forma análoga, então, Comolli (2008) vê uma íntima conexão entre esse modo de ficção comercial e a sociedade do espetáculo:

Triunfo da sociedade do espetáculo a constatar-se neste duplo movimento de generalização [por um lado, o "roteiro" é retirado do campo da ficção cinematográfica para servir às ficções políticas, econômicas, sociais ou militares] e de enrijecimento [por outro, um programa rígido regendo a construção das ficções industriais] do roteiro. Assim como o mercado, o espetáculo incita a estandardização. (COMOLLI, 2008, p.171)

Ou seja, por um lado, a vida social, econômica e política passa a imitar a ficção cinematográfica de viés representacional; por outro, as ficções cinematográficas não fariam outra coisa do que 
reforçar essa roteirização. Roteiros que se abrem para o risco do real seriam, antes de mais, roteiros em que essa prévia roteirização das relações sociais intersubjetivas, ou seja, dada como ponto pacífico, seria questionada; roteiros abertos (ao risco do real) seriam aqueles para quem a roteirização não fosse mais um modelo a ser seguido, mas sim um problema.

Assim, no cinema documentário haveria, para Comolli (2008), uma política interna e um impulso emancipatório básico: a oportunidade de se evitar apenas divulgar e garantir da roteirização social e trabalhar sob o risco do real, questionando, no roteiro específico do filme, aquele roteiro geral que ordena a realidade. Em documentários contemporâneos como Grandes como o Mundo de Gheerbrant de 1998 ou clássicos como Moi, un Noir de Rouch de 1958, mas também em filmes de ficção, de Alemanha Ano Zero de Rosselini de 1948, e a E a vida continua... de Kiarostami de 1992, citados pelo próprio Comolli (2008), a questão não é “como fazer o filme?", mas "como fazer para que haja filme?"

A ideia de roteiro, finalmente, no sentido amplo empregado por Comolli (2008), implica uma visão do mundo fechada e uma descrição acabada. Por aqui, podemos nos aproximar do que o autor entende como real, aquele sob o risco do qual o documentário estaria ou deveria estar. Haveria uma separação entre o real e a realidade, já que nossas realidades seriam enquadradas por linhas de ordem, que estruturam "modelos que regulam os dispositivos sociais e econômicos que nos mantêm em sua dependência" (COMOLLI, 2008, p. 169). O real é aquilo que, abordado sob risco, implicaria também o risco de quebrar ou questionar os roteiros que, no sentido amplo, seriam como os dispositivos que materializam modelos e, assim, aparecem como uma espécie de anteparo, que nos protegeria do real, dispondo-nos de modos de falar da realidade como se ela fosse o próprio real, mas mantendo-nos protegidos do risco do real.

Existiria, portanto, o sujeito de uma enunciação narrativa cinematográfica, de um lado, e o real, por outro; mas, entre eles, o roteiro, no sentido amplo, como um dispositivo que, materializando 
uma ordenação social, cultural e política, não apenas determina o que é dizível e visível, mas também protegeria esse sujeito e sua enunciação do risco desse real. A noção de dispositivo aparece, portanto, diretamente conectada ao que Comolli (2008) chama de roteiro. Se os roteiros formam modelos de pensar e agir, estes moldam os dispositivos sociais e econômicos, isto é, os meios pelos quais eles, os modelos, se materializam, se concretizam.

Na definição foucaultiana, dispositivos aparecem justamente como essa materialização, essa positividade de modelos, linhas de força, jogos e relações que traduzem as relações de poder que os ancoram. Para Foucault, um dispositivo é:

Um conjunto decididamente heterogêneo que engloba discursos, instituições, organizações arquitetônicas, decisões regulamentares, leis, medidas administrativas, enunciados científicos, proposições filosóficas, morais, filantrópicas. Em suma, o dito e o não dito são os elementos do dispositivo. O dispositivo é a rede que se pode tecer entre estes elementos (FOUCAULT, 2000, p. 244).

Em sua leitura do conceito foucaultiano, Agamben (2005) aponta para o fato de Foucault inicialmente adotar o termo positividade para estudar a relação dos indivíduos com o elemento histórico composto pelas instituições, regras e relações de poder. Somente mais tarde, esse termo é substituído por dispositivo. Segundo Agamben (2005), uma origem provável é o latim dispositio, termo usado pelos padres latinos ao traduzirem textos gregos que tratavam da oikonomia. Esta, por sua vez, era usada na teologia cristã, referindo-se à Santíssima Trindade, para definir "um conjunto de práxis, de saberes, de medidas, de instituições cujo objetivo é de administrar, governar, controlar e orientar, em um sentido em que se supõe útil, os comportamentos, os gestos e os pensamentos dos homens" (AGAMBEN, 2005, p. 12). É, portanto, a relação entre um ser divino e sua materialização prática. Analogamente, Foucault (2000) teria usado dispositivo, segundo essa leitura de Agamben, 
no sentido dessa materialização, na prática social, das relações de poder que distribuem o que é pensável e dizível, determinando os modos de agir a partir desse a priori histórico.

A definição englobaria, então, três dimensões: os elementos referenciáveis citados por Foucault (2000), como os discursos e as instituições; a conexão entre esses elementos, em configuração de rede; e a episteme, ou as formações discursivas sobre essa conexão, sendo expressamente dita ou não. E essas três dimensões ordenam a vida social, compondo dispositivos reguladores que vão "conduzir o corpo social a um certo efeito de subjetivação, seja ele de normalidade ou de desvio" (PARENTE, 2007, p. 10). Uma vez que essa subjetivação ocorra, os indivíduos passam a agir mediante a influência direta desses dispositivos.

Ora, roteiros, no sentido geral de Comolli (2008), poderiam ser pensados, assim, como dispositivos no sentido foucaultiano, isto é, meios discursivos e formais através dos quais enquadramos nossos modos específicos de agir, o que repercutiria nos modos como as pessoas compreendem a si próprias e falam delas mesmas. No caso do documentário, ou de uma ficção que não se orienta apenas por demandas formais a priori, como aquelas no modelo representacional clássico, isso é crucial: entre o realizador e o "real", intervêm sempre roteiros que alinham os modos de agir e pensar, de se compreender e falar de si.

Mais interessante nesse contexto, porém, seria a leitura de Deleuze (1990), que aponta na conceituação de Foucault não apenas linhas de sedimentação dos dispositivos, como a episteme, discursos e instituições.

Há linhas de sedimentação, diz Foucault, mas também há linhas de "fissura", de "fractura". Desenredar as linhas de um dispositivo, em cada caso, é construir um mapa, cartografar, percorrer terras desconhecidas, é o que ele chama de "trabalho de terreno". É preciso instalarmonos sobre as próprias linhas; estas não se detêm apenas na composição de um dispositivo, mas atravessamno, conduzem-no, do norte ao sul, de este a oeste, em 
diagonal. (DELEUZE, 1990, p.1).

Essas linhas de fissura estariam vinculadas a uma dimensão pouco explorada por Agamben (2005): as linhas de subjetivação. Por um lado, há subjetivações quando modos de agir encontram-se moldados pelos dispositivos de poder; por outro, cria-se também um jogo, uma possibilidade de ruptura, quando linhas de subjetivação permitem escapar ou pelo menos complexificar as relações de poder preexistentes. Em nosso contexto, ou seja, num comentário ao texto de Comolli (2008), o importante nessa leitura é que ela abre o campo para pensarmos que, embora os dispositivos estabeleçam formas fechadas de pensar o real, atualizando-o em realidades conforme modelos, há também possibilidades de ruptura.

Esta dimensão do "Si Próprio" (Soi) não é de maneira nenhuma uma determinação preexistente que se possa encontrar já acabada. Pois também uma linha de subjectivação é um processo, uma produção de subjectividade num dispositivo: ela está pra se fazer, na medida em que o dispositivo o deixe ou torne possível. È uma linha de fuga. Escapa às outras linhas, escapase-lhes. O "Si Próprio" (Soi) não é nem um saber nem um poder. É um processo de individuação que diz respeito a grupos ou pessoas, que escapa tanto às forças estabelecidas como aos saberes constituídos: uma espécie de mais-valia. Não é certo que todo dispositivo disponha de um processo semelhante. (DELEUZE, 1990, p. 3)

Essa dimensão apontada por Deleuze (1990) é fundamental para que pensemos, com Comolli (2008), a possibilidade de "escrituras" (roteiros em sentido específico) que, correndo o risco, provocam encontros com o real capazes de não apenas referi-lo como dados, mas abri-lo como experiência, isto é, considerá-lo não apenas como atualidade, mas como potência. Segundo suas palavras, daquela dificuldade que lhe é imposta de alguma maneira de fora, o cinema documentário tira todas as suas riquezas. Obrigação de 
experimentar, de tentar aproximações ajustadas às armadilhas sempre novas do mundo a filmar. Obrigação de imaginar, de testar, de verificar os dispositivos da escritura - inéditos na medida em que eles só podem estar intimamente ligados a um lugar particular, um traço do mundo. Além disso, esses dispositivos de escritura (grifo nosso), cada vez contingentes a um estado determinado de lugares, são eles mesmos submetidos à pressão do real (COMOLLI, 2008).

Dispositivos de escritura, isto é, roteiros em sentido estrito, pensados sob a pressão do real e sob risco desse encontro com ele, seriam justamente os meios pelos quais o documentarista poderia romper ao mesmo tempo com os roteiros em sentido amplo, questionando ou pelo menos complexificando as relações de poder subjacentes aos modos de discurso e ação social, e com aqueles roteiros em sentido específico que, supostamente operando no terreno de realidades atualizadas, apenas mimetizam e reforçam os primeiros.

\section{O filme dispositivo e os dispositivos sociais}

Numa perspectiva que remonta, em última instância, a Jean Baudry, mas que sofre diversas mudanças de foco e arcabouço teórico (XAVIER, 2005), a expressão filme-dispositivo é hoje corrente para se referir a certos filmes, seja de ficção ou documentários, em relação aos quais a força analítica do conceito clássico de mis-en-scène já não seria suficiente. Como nos aponta (referindo-se, por sua vez, a Patrice Blouin, Olivier Joyard, Luc Moullet e Adrian Martin), Luiz Carlos Oliveira Júnior: "se, nos anos 1950, a palavra mágica da crítica de cinema era mis-en-scène, na passagem dos anos 1990 para os 2000, época em que se fala no fim do maneirismo, outra ferramenta teórica ganha a dianteira: o conceito de dispositivo."(OLIVEIRA JUNIOR, 2013, p. 137) No Brasil, Jean-Claude Bernardet (2004) já mobilizara esse conceito para referir-se a Dez, de Abbas Kiarostami, um autor citado pelo 
próprio Comolli (2008). No que nos interessa mais diretamente aqui, Consuelo Lins (2004) e Cezar Migliorin (2010) tratam de filmes de Eduardo Coutinho segundo essa perspectiva.

Partindo das ideias de Comolli (2008), Migliorin (2005) aponta como filmes dispositivos seriam constructos capazes de disparar "um movimento não presente ou pré-existente no mundo, um acontecimento não dominado pelo artista". É por isso que Migliorin (2005) irá chamá-los de estratégia narrativa. Importante aqui destacar que, diferente do documentário que gostaria de registrar/exibir/expressar uma realidade que, por mais problemático que se mostre o acesso a ela, seria referenciada como um corpo de acontecimentos e fatos exteriores ao filme, o documentário que se apresenta como filme-dispositivo pretende acionar o real internamente, isto é, gerando, em si mesmo, um acontecimento que não existiria não fosse a agência do dispositivo criado pelo cineasta. Em um documentário-dispositivo, o documentarista concebe, através de uma estratégia particular, uma situação, monta o "tabuleiro do jogo" e dispõe algumas regras, que provoquem os personagens envolvidos a agirem e a falarem de si dentro desse jogo.

Essa ação não poderia ser prevista pelo diretor. Por isso, onde Comolli fala em "abandono do roteiro", Migliorin (2005) fala em "desprogramação", ou seja, "o surgimento de acontecimentos, a partir de um dispositivo, pressupõe um desdobramento dos corpos e subjetividades em possibilidades que ultrapassam suas próprias medidas; ultrapassam qualquer medida previamente pensável" (MIGLIORIN, 2005). Assim, a imagem do "documentáriodispositivo" será o seu próprio processo. Esse desenrolar de acontecimentos a partir das reordenações, invenções, criações e relações dos participantes. E porque produz esse processo, ele aciona um real que não existiria sem o filme.

Já que esse tipo de documentário opera como um recorte do real, ele também é um recorte do tempo. Não importa saber como era a situação dos personagens e dos lugares no passado precedente 
ao dispositivo e nem, tampouco, como será o seu futuro. $\mathrm{O}$ foco está no dispositivo, nas ações em seu interior, nos acontecimentos desencadeados. Nesse sentido, o dispositivo é sempre um presente não reproduzível (MIGLIORIN, 2005).

Podemos pensar nesse documentário como uma arte de experiência, da qual nenhum envolvido, inclusive o documentarista, pode prever o resultado. Nem mesmo se haverá um resultado.

O dispositivo pressupõe duas linhas complementares: uma de extremo controle, regras, limites, recortes; e outra de absoluta abertura, dependente da ação dos atores e de suas interconexões; e mais: a criação de um dispositivo não pressupõe uma obra. $\mathrm{O}$ dispositivo é uma experiência não roteirizável, ao mesmo tempo em que a utilização de dispositivos não gera boas ou más obras por princípio (MIGLIORIN, 2005).

Com essa ideia de filme-dispositivo, podemos pensar então o que seria esse documentário-dispositivo que, ao invés de legitimar e garantir os modelos da sociedade do espetáculo, visa justamente o contrário: seu questionamento como ação e fala modelar. Um dispositivo que seria, portanto, diferente dos dispositivos modelares (roteiros, no sentido amplo de Comolli) um "contra-dispositivo".

O que mais chama atenção em Moscou, no entanto, como uma novidade em relação até mesmo às obras anteriores de Eduardo Coutinho, é que, conforme aponta o próprio Migliorin.

Depois de vários filmes em que o risco da própria existência do filme mobilizava o espectador, mas em que algo se atualizava, a noção mesma de fabulação - tão utilizada para pensarmos a obra de Coutinho, implica uma atualização, uma organização da memória e dos eventos que inventam um mundo, uma pessoa, inexistente até então. Em Moscou, a concentração parece se deslocar de maneira incisiva para a individuação, para o coletivo, para o que faz a passagem entre as atualizações. (MIGLIORIN, 2010, p.15-16) 
Nesse sentido, para Migliorin (2010), Moscou se junta a outros filmes como Notas Flanantes de Campolina de 2009, Sábado à Noite de Araújo de 2007, e Encruzilhada Aprazível de Vasconcelos de 2007 por forçar os limites do próprio dispositivo e de sua capacidade de criar um real que não preexiste ao filme. Esses documentários iriam um pouco além por "desconfiarem do dispositivo e mesmo do encontro e praticamente evitarem que algo realmente se atualize" (MIGLIORIN, 2010, p. 16, grifo nosso). O que está grifado por nós é fundamental em nossa argumentação: é justamente por operar no campo da potência do encontro, da fabulação e dos personagens e praticamente evitarem que se atualizem no filme, que Moscou pode ser visto como exemplo de um filme em que o real aparece como algo que é da ordem do risco, isto é, nunca como uma realidade, seja ela preexistente ao filme, seja até mesmo criada dentro do filme (como, por exemplo, no documentário performativo tradicional). Se há essa esquiva de atualização e estímulo da potência, o real aparece no filme somente por via de referência indireta.

Se é assim, por quais procedimentos, instauradores do seu dispositivo, Coutinho obtém essa referência indireta ao real como potência? Temos uma hipótese: por multiplicação de referentes, evitando sua atualização num sentido final ou unívoco.

\section{Moscou como filme-dispositivo: emancipação e potência do real}

Três cenas parecem fundamentais em Moscou para apresentá-lo não só como um filme-dispositivo, mas sobretudo para entender em que sentido o próprio real, nele, não se atualiza.

A primeira cena é, como era de se esperar, aquela em que, sentados lado a lado, Eduardo Coutinho e Enrique Díaz chamam o grupo Galpão e explicam a proposta do filme. Eles terão três semanas para ler, interpretar e tentar realizar alguma coisa com o 
o texto, já fragmentário, de Anton Theckov - As três irmãs. Desde o início, há uma sensação de apreensão, que Enrique expressa dizendo que, dado o pouco tempo, não é possível prever o que vai acontecer. Visto do ponto de vista de Coutinho, que agora já se retirou de quadro, é como se o filme estivesse muito mais naquele horizonte apontado por Comolli (2008) - como fazer para que haja um filme - do que na preocupação sobre como fazer o filme: o que há para que haja o filme? Nesse momento de saída, nada. O filme poderá não se fazer ou ser sobre nada. E, de fato, o filme não se atualiza, porque não se concretiza a peça como um todo ou mesmo uma leitura da peça. Isso é, de certa forma, um receio expresso pelo próprio diretor (do filme), pelo diretor (da peça) e pelos atores: tomamos contato com fragmentos, exercícios de atuação e encenação. A princípio isso parece espontâneo, mas iremos perceber que não é bem assim, dado o trabalho da câmera e da presença de elementos que denunciam o dispositivo. Neste caso, o filme priva o espectador de ser recompensado em sua tarefa de tentar ir constituindo um sentido mais preciso. A expectativa inicial é de que as coisas caminhem numa direção. Neste aspecto, quase poderíamos dizer que o filme contém um procedimento típico de uma narrativa clássica: um prazo final (BORDWELL, 2005). Disparado o dispositivo, a expectativa do espectador é direcionada para a solução do problema que ele coloca no real. Mas se é para o filme se fazer, seria preciso que o filme caminhasse desse impulso inicial para alguma coisa, para uma configuração mais exata a partir desses fragmentos de texto e de logística de leitura dele por parte do grupo.

A segunda cena fundamental, que instaura na narrativa quase que um dispositivo dentro do dispositivo, complexificando-a, é aquela em que Enrique Díaz propõe aos atores falarem de uma lembrança e de uma preocupação atual. Essa cena dispara um mecanismo secundário que nos parece chave para compreender como o filme irá se desenvolver: ele cria, para o espectador, uma mistura de referentes das falas e ações, o que, por sua vez, irá 
mobilizar diferentes estratégias de filmagem e montagem. É que essas lembranças e preocupações que, supostamente são dos atores, seguirão duas direções.

Em primeiro lugar, elas se misturarão num segundo exercício: um ator falará das lembranças e preocupações dos outros. Nesse primeiro momento, podemos dizer que o filme não se atualiza porque esse exercício não parece, pelo menos a princípio, chegar em algum lugar. Mas isso é apenas aparente, porque, embora não se atualize numa direção esperada, repercute diretamente sobre o dispositivo principal do filme, que é o rumo que a própria peça está tomando.

Num segundo momento, mais importante, esses conteúdos - cujo referentes são, inicialmente, a vida passada e presente de um ator específico e depois podem se embaralhar, sendo que um ator empresta corpo e voz aos conteúdos de outros - passam agora se misturar com as falas oriundas do texto de Tchekhov. E aqui ficará claro que os "personagens" como que se desfiguram e já não sabemos a que referir falas e ações: primeiro, não sabemos mais de quem são as lembranças e preocupações, se pertencem a este ou àquele ator; segundo, não sabemos exatamente distinguir o que é texto theckhoviano (um texto que já é constituído de fragmentos) e o que é texto criado pelo grupo a partir da proposta feita por Coutinho e, depois, por Díaz, seguindo, de acordo com suas palavras na cena em que se anunciou o dispositivo, as "orientações do chefe".

Consolidada essa mistura de referentes do texto, podemos então chegar à terceira cena fundamental para nossa leitura que é aquela em que o personagem Andrei dialoga com o pai, apresentando seu filho. Isso é feito com o ator sentado de frente para uma outra cadeira, onde vemos um retrato antigo. $\mathrm{O}$ ator se refere a este retrato como sendo seu pai, o comandante, e fala de seu próprio filho, que acabou de nascer. Está bêbado, continua bebendo. Apresenta o filho, um menino (também representado por uma fotografia), como quem cumpre uma obrigação e refere-se a si mesmo como alguém que não teria cumprido as expectativas do pai. Mas o mais instigante é 
que justamente esse ator, no momento anterior de apresentar uma preocupação atual, havia dito que sua mulher estava prestes a dar à luz. Segundo sua fala (verdadeira? pertencente a ele mesmo ou a outro ator?).

Uma salva de... Uma salva de tiros para o novo netinho do vovô. O netinho do comandante. Olha só comandante. É a sua cara. Olha só que bonitinho. Coloca então as fotos do menino ao lado da foto do pai (como quem colocasse o bebê em seu colo). Tim tim. Eu não sou professor lá da Universidade de Moscou. Eu sou secretário do conselho. Secretário do conselho, comandante. Eu sei que não era bem isso que o Sr. queria. Não era bem isso que o Sr. sonhou. Tanto curso, tanta coisa. Mas agora... Mas o menino vai ser; e é homem. É homem, comandante. Eu sabia. Tava na barriga da mãe e eu sabia que era homem. [...] (MOSCOU, 2009)

Aqui fica claro que o espectador não encontrará um referente preciso. Naturalmente, não se trata de uma abertura total. Há um horizonte de significantes possíveis: de um lado, a preocupação atual de um ator (seja deste que está em cena ou não; exista essa preocupação na realidade de algum ator ou tenha sido inventada) e, de outro, o texto de Tchekov. Como decidir? Essa imprecisão é que torna esta uma experiência real (e não uma remissão a uma realidade externa ao filme, referida como algo que precisa ser buscado fora da própria experiência).

Essa duplicação ou imprecisão das falas repercute diretamente na imprecisão da câmera e do som, além da montagem. Essa cena replica um procedimento que vemos muitas vezes ao longo do filme: oscila-se entre uma câmera que observa, como quem registra ou flagra um ensaio, e uma câmera marcada para a encenação. Nessa segunda função da câmera há, aqui, primeiro um insert da fotografia do menino ao pé do porta-retrato da foto do pai; um close up que aparente cumprir não uma função observacional, mas uma função narrativa, como se filmasse a cena não documental, 
mas a ficcional, como se já estivesse pronta. Depois, mais claramente com uma função narrativa, o enquadramento da parte final da fala, quando o personagem está segurando uma carta e uma outra foto, de si mesmo. 'Lembra disso? Única foto de um professor que o Sr. vai ter na vida. Pelo menos minha. Que eu sou um merda do conselho. Comandante..." (MOSCOU, 2009).

Aqui, nessa parte final da fala, que termina quando o ator, após dizer "Comandante" serve-lhe mais um gole de bebida, um corte marca uma passagem de tempo, como uma pequena elipse narrativa. Então a montagem intervém, neste final de cena, como uma articuladora de sentido, mas não mais do ator ensaiando ou se exercitando na encenação de um trecho da peça, mas atuando como um personagem pronto, acabado.

Ora, se as falas e imagem (e som, como a música que por vezes oscila entre diegética e sincronizada com alguém tocando um teclado no teatro onde ocorrem os ensaios) estão o tempo todo em estado de flutuação de significantes, os referentes tornamse imprecisos, e essa sensação de imprecisão mesclada com uma aparência de inteligibilidade é que nos parece chave no jogo criado no filme. Poderíamos dizer, então, que o real está não diretamente referido, mas sempre em estado de potência: potência de filme, potência de peça, potência de personagens. E esse é, talvez, o sentido mais estrito de uma ausência de atualização que é constitutiva do filme com um todo: os personagens quase não existem, mas flutuam pelos corpos dos atores. Na parte final do filme, atores diferentes poderão interpretar um mesmo papel e aparecerem em cena, misturando, às vezes, suas falas. É o caso do personagem Andrei que, revelando para as irmãs que hipotecou a casa, é interpretado por dois atores diferentes. Um exercício? São os atores testando quem irá fazer o papel? Talvez não seja (ou não seja apenas) isso, porque, no fundo, a mescla de corpos e vozes nos fazem ver que há um personagem ali, mas não está atualizado neste ou naquele corpo, neste ou naquele ator. Os personagens e as situações seriam, assim, reais, mas por estarem justamente imprecisas e flutuantes, sem se 
concretizarem ou se atualizarem diretamente como realidades.

\section{Considerações finais}

Essa análise leva-nos, finalmente, a uma questão subsequente: seria a consciência do dispositivo no documentário, algo que pode levar o espectador a uma consciência do dispositivocinema como tal e, mais ainda, dos próprios dispositivos sociais?

Passar dos dispositivos sociais para o dispositivo cinematográfico implica uma mudança de enfoque. Porque os dispositivos sociais seriam da ordem de uma agência não controlada e, grosso modo, sem sujeito. Os dispositivos sociais funcionam de maneira anônima, isto é, não por intenções. Quando transitamos para o terreno da arte e do cinema, o que está em jogo é a criação intencional (embora não de todo controlada em seus resultados) de um dispositivo, da estruturação de uma forma que emoldura o surgimento de um real, implicando o jogo entre controle (na concepção e no início do processo) e descontrole (no nível dos resultados).

Poderia, então, esse dispositivo inventado num filmedispositivo dar a ver algo mais sobre os próprios dispositivos sociais, anônimos? Formulando à maneira de Comolli (2008): poderia o roteiro do filme, em sentido estrito, se constituir com um anti-roteiro, isto é, contra os roteiros que moldam nossas fantasias e ações? Poderia, enfim, a percepção do modo como um dispositivo específico, inventado num documentário, por exemplo, cria um real (ao invés de representar uma realidade pré-existente) abrir a percepção para o fato de que, afinal, mesmo que anônimos, sem sujeito, quaisquer dispositivos de controle são um modo de estabelecer as rédeas da realidade e não o real em si mesmo? Esta é uma questão ampla, mas é algo que podemos ter no horizonte ao falarmos de filmes-dispositivos como Moscou. Seu caráter artificioso de invenção de um dispositivo de abertura ou mesmo criação de um real talvez contenha, implicitamente, uma política e 
uma intenção de fundo emancipatória, revelando, nisso, o caráter artificialista (em oposição a uma atitude naturalizante) das estruturas sociais dadas em uma sociedade.

Seria, assim, para concluir, na busca de ruptura com os dispositivos sociais, que materializam relações de poder estabelecidas que o risco do real apareceria para o documentarista. Um documentário-dispositivo, tal como o que Coutinho criou em Moscou, poderia, então, servir como uma espécie de contradispositivo, um mecanismo de emancipação não porque incorpora, denuncia ou mesmo transforma uma realidade, mas porque, criando um real, deixa a vida em certo estado de suspensão de juízo e de saber sobre o mundo.

\section{Referências}

AGAMBEN, Giorgio. O que é dispositivo?. 2005. Disponível em: $<$ http://periodicos.ufsc.br/index.php/Outra/article/view/12576>. Acesso em: 20 jun. 2015.

- A potência do pensamento. Revista do Departamento de Psicologia, Niterói, v. 18, n. 1, p. 11-28, jan./jun., 2006.

BERNADET, Jean-Claude. Caminhos de Kiarostami. São Paulo: Companhia das letras, 2004.

BORDWELL, David. O cinema clássico hollywoodiano: normas e princípios narrativos. In: RAMOS, Fernão Pessoa (Org.). Teoria Contemporânea do cinema. São Paulo: Senac, 2005. v. 2.

COMOLLI, Jean-Louis. Ver e poder- A inocência perdida: cinema, televisão, ficção, documentário. Belo Horizonte: UFMG, 2008.

DELEUZE, Gilles. Que és un dispositivo? In: . Michel Foucault, filósofo. Barcelona: Gedisa, 1990. p. 155-161. Disponível 
em: <http://eps.otics.org/material/entrada-outras-ofertas/artigos/ gilles-deleuze-o-que-e-um-dispositivo/view $>$. Acesso em: 25 jun. 2015.

FOSTER, Hal. O retorno do real: a vanguarda no final do século XX. São Paulo: Cosac Naify, 2014.

FOUCAULT, Michel. Sobre a História da sexualidade. In:

Microfísica do poder. Rio de Janeiro: Graal, 2000, p. 243-27.

JAGUARIBE, Beatriz. O choque do real: estética, mídia e cultura. Rio de Janeiro: Rocco, 2007.

LINS, Consuelo. O documentário de Eduardo Coutinho: televisão, cinema e vídeo. Rio de Janeiro: Jorge Zahar, 2004.

LOPES, Denilson. No coração do mundo. Rio de Janeiro: Rocco Digital, 2012.

MARGATO, Izabel; GOMES, Renato Cordeiro. (Org.). Novos realismos. Belo Horizonte: UFMG, 2012.

MOSCOU. Direção de Eduardo Coutinho. Produção Executiva de João Moreira Salles, Mauricio Andrade Ramos e Guilherme Cezar Coelho. Rio de Janeiro: VideoFilmes, 2009. vídeo, 80 min.

MIGLIORIN, Cezar. Documentário recente brasileiro e a política das imagens. In: . Ensaios do real. Rio de Janeiro: Azougue, 2010 .

. O dispositivo como estratégia narrativa. Digitagrama, Rio de Janeiro, 2005. Disponível em: <http://www.estacio.br/ graduacao/cinema/digitagrama/ numero3/cmigliorin.asp $>$. Acesso em: 21 jun. 2015. 
OLIVEIRA JÚNIOR, Luiz Carlos. A mise-en-scène no cinema: do clássico ao cinema de fluxo. Campinas: Papirus, 2013.

PARENTE, André. Cinema em trânsito: do dispositivo do cinema ao cinema do dispositivo. In: PENAFRIA, Manuela; Índia Mara MARTINS (Org). Estéticas do digital: cinema e tecnologia. Covilhã: Labcom, 2007.

RANCIÈRE, Jacques. A partilha do sensível: estética e política. São Paulo: Editora 34, 2007.

. A fábula cinematográfica. São Paulo: Papirus, 2001.

SCHOLLHAMMER, Karl Erik. Realismo afetivo: evocar realismo além da representação. Estudos de literatura brasileira contemporânea, Rio de Janeiro, n.39, p. 129-148, jan./jun. 2012.

XAVIER, Ismail. O discurso cinematográfico: a opacidade e a transparência. São Paulo: Paz e Terra, 2005. 